\title{
Confucius's Marketing Communication from the Perspective of 4R
}

\author{
Qiao Lirong \\ Qilu University of Technology (Shandong Academy of Sciences), Ji'nan, Shandong 250353, China \\ qiaolirong@126.com
}

Keywords: 4R theory, tourism performance brand, large-scale original dance drama "Confucius" marketing communication.

\begin{abstract}
R theory's understanding of marketing elements has adapted to the new situation of modern tourism market, which is becoming more and more complicated, networked and highly related from transaction to relationship. It is of strategic guiding significance to the marketing and communication of tourism performing arts brand. As far as the tourism performing arts drama Confucius is concerned, it is necessary to establish a highly responsive market response to the demand. Through contact communication, a diversified value relationship is created; through relationship marketing, brand equity is accumulated and disseminated; through win-win, a multi-dimensional value return is built; it is conducive to releasing the brand in Qufu Confucius cultural industry in the driving effect, and enhancing the brand value of Confucius.
\end{abstract}

\section{Introduction}

With the vigorous development of domestic tourism and the improvement of tourists'cultural taste, the tourism performing arts industry has sprung up. A group of Tourism Performing Arts products with local cultural characteristics have been continuously developed. One of them is Confucius, a large original dance drama planned and created by Qufu Municipal Government, Qufu Cultural Tourism Development Investment Group and Qufu Confucius Cultural Performing Arts Co., Ltd. Facing the market competition day, Tourism Performing Arts products tend to be homogeneous. How to continuously bring unique cultural experience to tourists and establish a long-term relationship with tourists has become a realistic topic of Tourism Performing Arts products marketing and communication. Tourism performing arts products are the integration of tourism, culture and performance and other factors of production, reflecting a specific regional culture, emphasizing experiential and participatory thematic commercial performance; [1] (p44-50); is the main tourist participation in tourism production, publicizing their own specific identity and cultural form of means. [2] (p790) This determines that its marketing activities must be in more complex market relations and cultural relevance. The 4P and 4C of traditional marketing can not realize the marketing goal of long-term ownership of tourists'identity, making them willing to consume and actively disseminate, nor can it solve the deep-seated needs of tourists in the increasingly individualized and scattered market segmentation.

As the product of the paradigm evolution of marketing theory, Schultz's 4R marketing, namely: reaction, relativity, relationship, retribution. [3] (p454), which is different from traditional marketing in that it is relationship marketing as the core and competition-oriented, "from emphasizing the development of transactions to emphasizing the lasting relationship with customers and related stakeholders", [4] (p48) because it introduces a variety of factors such as consumers, products and brands, media, market relations and returns as a whole, Promote enterprises to create demand initiatively and establish new long-term, strategic and win-win relationships among enterprises, consumers and relevant stakeholders in a more effective way at a higher level. The author thinks that this theory has more pertinence to the marketing and communication of Confucius, which will be analyzed from four aspects: relevance, relationship, reaction and return. 


\section{Facing competition, establishing a highly responsive market response}

Under the framework of $4 \mathrm{R}$ theory, the response is to improve the response speed and responsiveness of enterprises to the market, and to establish a high response mode to demand in the market competition with mutual penetration and influence. When Qufu's tourism enterprises launched Confucius, they chose a market response model which is competitive-oriented, market-oriented and serving the development strategy of Confucius'cultural industry, and also meets the needs of Confucius' own development.

First, to create "Confucius" is in line with the strategic requirements of Qufu's development of Confucius's brand culture industry. In 2008, the cultural industrial park of Qufu new district was officially listed as a national cultural industry demonstration park. Qufu urgently needs high-standard cultural products to match it to further stretch the value of Confucius cultural brand. Therefore, the Municipal Government supported Qufu Cultural Tourism Development Investment Group to raise more than 50 million yuan, hired first-class artists to compile "Confucius" as a "leader" in the implementation of Confucius'cultural industry, and won the qualification of national key tourism and cultural projects for it. This strategic orientation and action not only clarifies the priority of Confucius in policy and resource allocation, but also, according to the new understanding that "tourism performing arts are the path of traditional cultural resources conversion and cultural capital spillover"[5] it is very possible to change the traditional tourism mode of "watching temples in the daytime and sleeping in the evening" in Qufu. To achieve one of the transformation forms of Qufu's tourism industry transformation and upgrading.

Secondly, the creation of Confucius satisfies the public's cognition of Confucius and his thoughts, wisdom, emotions and mentality, and the need to identify with national culture. Tourism is essentially a cultural and leisure experience. After the return of Confucius, tourists often intentionally feel exhausted, and the appearance of Confucius can make up for the lack of such experience. The implication of Confucian culture endows the drama with distinctive brand characteristics and unique symbolic value. The image of Confucius and its ideological essence, after more than 2500 years, have accumulated in the character of the Chinese nation, the blood of the Chinese people around the world, is the significance of national identity and cultural belonging. The appearance of Confucius makes the tourists change from purely visiting famous mountains, rivers, scenic spots and historical sites into a process of spiritual perception, which is beneficial to people's feeling of identity confirmation and cultural identity different from daily life. This is the unique personality that Confucius can become a brand and the value that other performing arts brands can not have. Provide.

Third, the introduction of "Confucius" helps to establish its competitive advantage in the Jiangbei entertainment market. According to the analysis of the industry experts, China's tourism performance market has entered a diversified pattern of flourishing flowers, brand competition, Jiangnan performance market development early, relatively mature, there are well-known brands "Yunnan Image", "Impression Liu Sanjie", "Impression Lijiang", "Songcheng Thousand Years of Love", "Dream Lijiang" and so on; Jiangbei's well-known tourist repertoires are listed on the list besides Dengfeng's Shaolin Music Canon, Qufu's Confucius, Qingdao's Blue Imagination, Taian's Zen Canon, Weihai's Hua Xia, and Linyi's Mengshan Yishui. The selling point of these plays is the live performance, and the brand competitive advantage of Confucius lies in the content and cultural resources. On the one hand, the drama incorporates the intangible cultural heritage elements of Confucian music and dance, forming a unique point of view. On the other hand, as the hometown of saints and the birthplace of Confucian culture, Qufu enjoys not only monopoly of Confucian cultural resources, but also international fame and unique attraction in the world cultural geography, especially in Southeast Asian cultural circle and Chinese sacrificial cultural circle. People's pull and core competitiveness are greatly enhanced. 


\section{Through the contact transmission, create a variety of value relevance}

Different from the traditional marketing promotion association driven by pure benefit, Schultz Design Association establishes multi-directional correlation with consumers in business, demand and other aspects through an effective way to form a mutually beneficial, mutually demanding, mutually beneficial relationship to improve the brand reputation and the initiative of communication. Instead of maintaining an interactive relationship. This design embodies the concept of modern marketing, that is, marketing is not only a means, but also a series of communication process to create, disseminate, transfer customer value and customer relationship, which is used in brand communication, that is, the process of using brand value to manage customer relationship. For the travel drama Confucius, it means that there is a continuous interaction between tourists and the brand, which results from the exchange of information and the sharing of common cultural values. For this reason, the first thing Confucius has to do is to constantly explore the contact points with consumers, and to implement the program's information and value dissemination. Because in Schultz's view, each contact point is a communication tool, the so-called contact is the process and experience of communicating brand, product category, and any market-related information to consumers or potential consumers. According to the actual performance of Confucius's marketing communication, three contacts play a major role.

The first is the event touch point, mainly led by Qufu Municipal Government and Qufu Tourism Bureau, with the help of the international Confucius Cultural Festival, Confucius Ceremony, and the successful declaration of national key tourism and cultural projects and other hot issues of the sensation and pull effect, not only in Shandong TV, Qilu film and television, China News, China Report, China, and so on. Mass Daily and other important media specially reported the performance information of Confucius. It was also widely publicized on 93 national and local websites, such as Sohu Culture Channel, Sina. com, Tencent News Channel, Netease Finance Channel, China Cultural Creative Industry Network, Qufu People's Government Network, Qufu Tourism Network, Qilu Network, etc. Chuan quickly increased the exposure of the dance drama Confucius, making it the focus of the event, prompting the target tourist audience to learn about the origin, theme, content and viewing points of the travel drama Confucius. Through knowledge association, a positive imagination of the brand was formed and the brand's popularity was enhanced.

The second is the network contact, mainly under the participation of tourists to carry out interactive network communication. One way is for tourists to promote Confucius in public forums, Qilu communities, and Shengyuan forums in the form of impressions and soft texts, so as to attract the interest of the target tourist audience or the desire to communicate and express Confucius, and objectively extend the communication antenna of Confucius, thus contributing to the sustained attention to the brand. The other is that the host uploads the video clip of Confucius to Video websites such as Qianqin, Youku, Cool 6, Zhoulai and Shandong Network TV Network, which attract the attention of some netizens. Then these netizens quote or post it to the space of Sina blog, Tencent or Renren for their friends to share and discuss. For the two time. According to the author's statistics, from October 2010 to March 2016, "Confucius" in different video-on-demand total of 41760 times, 2236 quotations, 810 comments. In fact, the audience who have watched Confucius after two times of communication is far more than that. This interactive marketing makes full use of the unique viscous and diffusive advantages of network interpersonal communication. It is easy to cause the target tourists to actively spread Confucius. They are not only the terminal of brand communication, but also the starting point of brand communication. It facilitates the dynamic, continuous and deep communication between the target tourist audience and the brand, and satisfies their sense of participation and belonging to the specific cultural circle (community) of Confucius. It can be seen that this psychological and emotional connection is not only conducive to the brand and potential target audience to share the value of the interactive recognition, but also conducive to "individual mass.

The third is the product contact, mainly innovative Tourism Performing Arts product combination series, joint related brand (product) value-added marketing. As a major tourism brand 
in Qufu, Confucius has its own particularity. On the one hand, it is not an independent tourist attraction, must be attached to the tourist attractions (core heritage sites) and Confucius cultural industry and exist. On the other hand, it has a strong cultural attribute. It not only promotes the commercial performance process, but also includes the process of creating differentiated tourist audiences by giving meaning (thoughts, spiritual perception) to the performers and target tourists, and a process of value innovation by enhancing the added value of Confucius. According to this particularity, the tourists concerned not only produced a series of products with tourism-driven repertoire, such as "touring three Confucius-watching Confucius-studying Confucius" (studying the Analects of Confucius) - experiencing folk customs; viewing the old city of Ming Dynasty-watching Confucius-the World Confucian Congress, etc., but also developed a dance drama "Confucius" as the core, and among them. The performances are closely related to each other and have their own characteristics, such as "Confucius Music and Dance", "Ancient Music of the Lu State", "Sacred Dream of the Almond Altar", "Opening Ceremony of the Old City of the Ming Dynasty", "Opening Ceremony of Confucius Temple" and "Chinese Adult Ceremony". The combination of Confucius with different performing arts products and the reassembly of product mix and Confucius cultural heritage sites is a kind of value innovation, which not only enlarges the uniqueness of their products, but also makes them easy to show their inherent characteristics in the marketing and communication of different media because of the physical continuity of the core elements of creativity. It also lays a foundation for Confucius to provide customized, individualized and hierarchical services, and objectively discovers a stable group of tourists who have a sense of identity with Confucius, such as "a trip to sacrifice Confucius in a flourishing age", "a trip to parent-child cultural experience", "a trip to Chinese adults". Travel, Hong Kong, Macao, Taiwan, Southeast Asian overseas Chinese "root-seeking" tours, as well as "pilgrimage" tours from South Korea, Japan and Europe and the United States, Dr. Ji's study group in the United States, International Youth Cultural Tours in Shandong, and so on; moreover, it is more conducive to the "diversification of the tourist market", turning some ordinary tourists into the most valuable. Customers create customer value.

\section{Accumulate brand equity through relationship marketing}

The "relationship" in 4R theory emphasizes that the enterprise should cultivate and maintain the relationship with all stakeholders from the outside of the enterprise with the idea of optimization and system. This is the inevitable requirement for enterprises to create brand equity and the fundamental starting point for implementing brand marketing communication. True brand exists in the recognition and demand of stakeholders, and their continuous accumulation of brand support and trust constitutes brand equity. In this sense, the brand marketing communication of Confucius is the process of optimizing and managing its brand equity, and also the process of good relationship between management and stakeholders. Therefore, in addition to maintaining long-term communication with the target tourist audience, Confucius Culture and Performing Arts Company should also establish direct links with travel agencies, tourist investors, tourist enterprises in scenic spots, tourist performing arts brokerage organizations, tourist hotels, transportation systems, and local governments of provinces and cities, Tourism Administration bureaus, mass media, and Confucius Research. Developing indirect relationships, such as associations and Confucius Institutes, and trying to carry out joint marketing and communication with all stakeholders can enhance the market development and control capabilities of the partners, so that they can change from weak links to benefit sharing or strong links; only all stakeholders are duty-bound to assume the corresponding responsibilities. Marketing or communication roles can maximize and rationalize the benefits generated by such transformation.[13](P218). In relationship marketing, long-term trust and commitment based on benefit contract is the key variable to build stable and mutually beneficial relationship. [14] (p53-54) At present, Confucius lacks such a benefit contract among all the related subjects, and there is no corresponding benefit coordination mechanism to provide protection for it. This is a problem that Confucius must face up to and be solved urgently in future marketing communication. 


\section{Build a multi oriented value reward through win win}

The "return" in $4 \mathrm{R}$ theory focuses on the relationship between cost and profit, stressing that all marketing communication activities must create value for customers, and pursuing value return on the basis of win-win with stakeholders. Therefore, the value return of Confucius should be measured from five aspects: tourist audience, cooperative tourism enterprises, media, performers and social effects. The audience is mainly to enhance the "Confucius" brings tourists satisfaction, identity and sense of value; the interests of cooperative tourism enterprises are mainly reflected in the "Confucius" itself led by the audience to the target of the cooperative enterprise consumer group transformation success rate, the media benefit is the key to constantly explore all the news of "Confucius". And topic value, so that it can create listening and viewing effects for the media. The benefit of performers lies in improving their enthusiasm for innovative dramas and their sense of achievement through effective material and spiritual incentives; the social effect is to enhance the sense of mission and responsibility of performing arts enterprises in promoting local social progress, and to create a good image of "community citizens".

To sum up, as the innovation and development of traditional marketing, 4R's understanding of marketing elements has changed from transaction to relationship and communication, which reflects a great progress in modern marketing concept, that is, the rational economic man orientation, which maximizes the traditional profit, has more and more integrated the strategic thinking of the combination of holism and humanism. Dimension. The strategic goal of brand marketing and communication of the travel drama Confucius is to continuously develop, disseminate and manage brand equity, and fully release the driving effect of the drama in the Confucius brand culture industry. The "reaction", "connection", "relationship" and "reward" involved in the drama should be served and unified in this center, dynamic. Coordination and integration is the key to ensure the effective functioning of each mechanism and the positive feedback.

\section{References}

[1] Li Leilei, Zhang Ying, Lu Jiajie, et al. A case study of the theme park of Shenzhen Overseas Chinese Town, a cultural industry production model for tourism performance [J]. Tourism Science, No. 6, 2005.

[2] Yvonne Payne Daniel. Tourism Dance Performance Authentieity[J]. Anna1s of Tourism Research, 1996.

[3] Don Schultz, Heidi Schultz. Integrated Marketing Communications: Five Key Steps to Create Corporate Value. See Og Mandino. The World's Greatest Marketing Book [M]. Heilongjiang: Heilongjiang Science and Technology Press, 2008.

[4] Pierce, Wu Xiaoming, et al. Strategic shift in market orientation [M]. Beijing: Tsinghua University Press, 2005.

[5] The first China tourism performance culture summit. Speech by Professor Wang Yan, Department of tourism, Beijing Jiaotong University.

[6] Xu Shipi. Impact and Expansion of Chinese Traditional Performing Market by Tourism Performance [J]. Chinese Drama. No. 9, 2008.

[7] Tom Duncan.IM: Using Adervertising and Promotion to Built Brands [M]. Copy-right_2002 by the McGraw-Hill Companies. 